\title{
Causal Linkages among Advanced Emerging European and Asian Economies
}

\author{
Dilip Kumar \\ Indian Institutes of Management Kashipur, Kashipur, India \\ Email: dksic212@gmail.com
}

How to cite this paper: Kumar, D. (2019) Causal Linkages among Advanced Emerging European and Asian Economies. Theoretical Economics Letters, 9, 139-154. https://doi.org/10.4236/tel.2019.91012

Received: December 4, 2018

Accepted: January 29, 2019

Published: February 1, 2019

Copyright () 2019 by author(s) and Scientific Research Publishing Inc. This work is licensed under the Creative Commons Attribution International License (CC BY 4.0).

http://creativecommons.org/licenses/by/4.0/

\begin{abstract}
This study analyzes the causal interlinkages in the stock markets of advanced emerging European and Asian economies using Hong's [1] causality tests. Our empirical results provide evidence that direct and contemporaneous casual linkages among markets are weak. However, when we examine the indirect causal linkages, we find a significant return spillover effect in some cases.
\end{abstract}

\section{Keywords}

Causality-in-Mean, Causality-in-Variance, Return Spillover,

Volatility Spillover, Advanced Emerging European and Asian Economies

\section{Introduction}

The study related to causal interlinkages among various stock markets around the globe is crucial for institutional investors, hedge fund managers, portfolio managers and regulators. The emerging markets exhibit higher volatility and have plenty of opportunities for various market participants to make extraordinary gains in comparison to the opportunities available in the developed markets. In this paper, our interest is to investigate causal linkages among advanced emerging European and Asian markets (Czech Republic, Hungary, Poland, Turkey, Malaysia and Taiwan (China)). Table 1 presents the stock market indicators for the stock indices from the markets under study as of May 2012 and December 2009.

Among the given advanced emerging European economies, Turkey appears to be the largest economy based on the given market capitalization. If we include the Asian economies, then Taiwan (China) is the largest of all the markets under study based on the market capitalization in both the periods (December 2009 and May 2012). Of all the markets under study, only Malaysia has shown a 
Table 1. Stock market indicators.

\begin{tabular}{ccccccc}
\hline & \multicolumn{2}{c}{$\begin{array}{c}\text { Market capitalization } \\
\text { (in US\$ million) }\end{array}$} & \multicolumn{2}{c}{ Percentage of GDP } & \multicolumn{2}{c}{$\begin{array}{c}\text { Percentage of } \\
\text { world capitalization }\end{array}$} \\
\hline & May-2012 & Dec-2009 & May-2012 & Dec-2009 & May-2012 & Dec-2009 \\
\hline Czech & $38,094.00$ & $41,441.98$ & 23.39 & 21.79 & 0.08 & 0.09 \\
Hungary & $18,515.00$ & $30,100.10$ & 21.38 & 23.77 & 0.04 & 0.07 \\
Poland & $140,170.00$ & $150,641.00$ & 40.25 & 34.99 & 0.30 & 0.33 \\
Turkey & $224,383.00$ & $227,321.90$ & 40.85 & 36.99 & 0.48 & 0.50 \\
Malaysia & $404,987.00$ & $284,047.90$ & 170.82 & 147.24 & 0.87 & 0.62 \\
Taiwan (China) & $721,745.00$ & $733,052.40$ & 182.95 & 194.21 & 1.55 & 1.60 \\
\hline
\end{tabular}

significant increase in its market capitalization as a percentage of world markets' capitalization. Furthermore, Hungary and Taiwan (China) have shown a decrease in the values of market capitalization as a percentage of their GDP. This indicates that most of the markets under study have been adversely impacted by the recent European debt crisis.

The core aim of this paper is to investigate the causal interlinkages among the stock markets of advanced emerging European and Asian economies using a modified version of Cheung and $\mathrm{Ng}$ [2] (Hong [1]) causality tests that also account for contemporaneous causality. We apply Hong's [1] tests on the iid (independently and identically distributed) series and here it is the standardized residuals obtained from the best fit of the conditional volatility model estimated using weekly data of the stock indices under study. The markets under study have experienced a turbulent environment during the past decade and have also been important choices of most institutional investors and portfolio managers. Our empirical analysis contributes in the sense that we first incorporate the possible regime shifts in volatility using the MRS-GARCH model to explain the conditional volatility of the markets under study so as to investigate the causal inter-market linkages within each region and across regions of advanced emerging European and Asian economies as a whole.

The remainder of this paper is organized as follows. Section 2 presents the literature review. Section 3 reports the methodology used. Section 4 provides details on the data used and discusses the preliminary analysis. Section 5 provides the empirical results with discussion and Section 6 concludes with a summary of our main findings.

\section{Literature Review}

Billio and Pelizzon [3], Baele [4], Kim et al. [5], Bartram et al. [6] and Savva et al. [7] studied the interlinkages and spillover effects in major stock markets from the European economies. Koutmos [8] analyzes the dynamic return and volatility interactive relationship among the four major European markets and finds multidirectional lead/lag relationships among them. In addition, he finds evi- 
dence of a significant asymmetric volatility spillover among all the four markets. Baig and Goldfajn [9] examine the contagion between five major Asian financial markets and find evidence of a significant increase in currency and sovereign spreads during the period of the Asian crisis (1997-1998) but find mixed results for the equity market correlations. Forbes and Rigobon [10] find that correlation coefficients depend on the market volatility and provide adjustment for such bias. They find the evidence of a significant market co-movement during the period of the Asian crisis, Mexican devaluation and during the periods of US market crash in 1987. Fratzscher [11] finds evidence of exchange rate volatility to be an important factor in explaining the importance of volatility spillover between the US and European market. He also finds evidence of contagion from the US market to various European markets during the turbulent periods. Billio and Pelizzon [3] analyze the importance of crashes and crisis, deregulation, globalization and convergence of European economies as important factors in explaining the volatility transmission from the world index to various European markets using multivariate switching model. They find an increase in the volatility spillover effect from the world index and the German market to various European markets after the Economic and Monetary Union (EMU). Baele [4] investigates the impact of globalization and regional integration as important factors in understanding the stock market interlinkages with a focus on Western Europe. Using a regime switching, he analyzes the magnitude and time-varying nature of volatility spillovers from the aggregate European market and the US market to 13 local European equity markets and finds some evidence of contagion from the US market to various local European equity markets during the turbulent periods. Using the dynamic conditional correlation framework, Savva et al. [7] examine the impact of the introduction of the Euro on the interactive relationship between the stock markets of New York, London, Frankfurt and Paris. They find evidence of significant return and volatility spillover effect from foreign markets with asymmetries in volatilities and conditional correlations. Maneschiold [12] and Soofi [13] observe that the Turkish market returns are significantly impacted by the events in the US market based on the Granger causality test. Using the time-varying copula, Bartram et al. [6] analyze the influence of the introduction of the Euro on the dependence structure of 17 European stock markets and find increase in cross-dependence of larger European markets such as in France, Germany, Italy, the Netherlands and Spain. Using bivariate vector auto-regression generalized autoregressive conditional heteroscedasticity model, Lee [14] investigates the volatility spillover effect among six Asian stock markets (India, Hong Kong, South Korea, Japan, Singapore and Taiwan (China)) and finds statistically significant volatility spillover effects within the stock markets of these countries. Henry et al. [15] examine the impact of shocks to returns as important factor for information spillover among various South East Asian economies and find that negative-return innovation leads to higher levels of domestic volatility than a positive innovation of equal magnitude. Singh et al. 
[16] find that the regional influence is an important factor in explaining the return and volatility spillover effect between Asian and European stock markets. Beirne et al. [17] examine the volatility spillover between developed markets and emerging markets and find evidence of significant return and volatility spillover between developed and emerging markets.

\section{Methodology}

The study of causal inter-linkages among different stock markets began with the pioneering work of Granger [18]. It paved the way to examine the return and volatility transmission among different markets. Cheung and $\mathrm{Ng}$ [2] propose a modified form of the Granger causality test as a two-step procedure. According to Cheung and $\mathrm{Ng}$ [2], a stationary and ergodic process $\mathrm{X}$ is said to cause another stationary and ergodic process $\mathrm{Y}$ in variance if

$$
E\left\{\left(X_{t+1}-\mu_{x, t+1}\right)^{2} \mid I_{t}\right\} \neq E\left\{\left(X_{t+1}-\mu_{x, t+1}\right)^{2} \mid J_{t}\right\}
$$

where $I_{t}$ and $J_{t}$ are the information sets defined as $I_{t}=\left\{X_{t-j} ; j \geq 0\right\}$ and $J_{t}=\left\{X_{t-j}, Y_{t-j} ; j \geq 0\right\}$.

In the first step, a univariate GARCH model is fitted to both the processes, $X$ and $Y$, to separate out the standardized residuals to be used in the second step. As a preliminary step, we first compare the standard GARCH model and Markov regime switching GARCH model to identify the best model in terms of fitting the data well. In the second step, we estimate the cross-correlation function proposed by Hong [1] based on the standardized residuals and the squared standardized residuals to determine the return and volatility spillover effects. In the next sub-section, we describe the models used in this study.

\subsection{GARCH Model}

Suppose $p_{t}$ is the value of a stock market index at time $t$. Then, the continuously compounded return $r_{t}$ is given as:

$$
r_{t}=\ln \left(\frac{p_{t}}{p_{t-1}}\right)
$$

The standard generalized autoregressive conditional heteroskedasticity (GARCH) model is given as:

$$
\begin{gathered}
r_{t}=\delta+\varepsilon_{t}=\delta+z_{t} \sqrt{h_{t}}, \quad \varepsilon_{t}=z_{t} \sqrt{h_{t}}, z_{t} \sim N(0,1) \\
h_{t}=\alpha_{0}+\alpha_{1} \varepsilon_{t-1}^{2}+\beta_{1} h_{t-1}
\end{gathered}
$$

where $\alpha_{0}>0, \alpha_{1} \geq 0$ and $\beta_{1} \geq 0$.

\subsection{Markov Regime-Switching GARCH (MRS-GARCH) Model}

The general form of MRS-GARCH model is given as:

$$
r_{t}=\mu_{t}^{(i)}+\varepsilon_{t}=\delta^{(i)}+\varepsilon_{t}, \varepsilon_{t} \sim N\left(0, h_{t}\right)
$$




$$
h_{t}^{(i)}=\alpha_{0}^{(i)}+\alpha_{1}^{(i)} \varepsilon_{t-1}^{2}+\beta_{1}^{(i)} h_{t-1}
$$

where $h_{t-1}$ is a state-independent average of past conditional variances and $i=1$ and 2, the two states of the MRS-GARCH model which are indexed by an unobserved latent variable $S_{t}$ and it takes the values 0 and las per the state of the markets. The variable $S_{t}$ is assumed to follow a first-order Markov chain with a fixed transition probability matrix $P$ given by:

$$
P=\left[\begin{array}{ll}
p_{11} & p_{21} \\
p_{12} & p_{22}
\end{array}\right]=\left[\begin{array}{cc}
p & 1-q \\
1-p & q
\end{array}\right]
$$

where $p_{i j}=\operatorname{Pr}\left(S_{t}=j \mid S_{t-1}=i\right)$ for $i=0,1$. The ergodic probability to be in state $S_{t}=1$ is written as:

$$
\pi_{1}=\frac{(1-p)}{(2-p-q)}
$$

and the unconditional probability to be in state $S_{t}=0$ is written as:

$$
\pi_{2}=1-\pi_{1}
$$

Cai [19] and Hamilton and Susmel [20] find that in a regime-switching context, the maximum likelihood estimation not only depends on the entire past observable information but also depends on the current and past states. Gray [21] proposes a measure of $h_{t}$ that is not path dependent, in particular, Gray [21] proposes the use of information available at time $t-2$ to integrate the unobserved regimes and is written as:

$$
\begin{aligned}
h_{t-1}= & E_{t-2}\left\{h_{t-1}^{(j)}\right\}=p_{1, t-1}\left[\left(\mu_{t-1}^{(1)}\right)^{2}+h_{t-1}^{(1)}\right]+\left(1-p_{1, t-1}\right)\left[\left(\mu_{t-1}^{(2)}\right)^{2}+h_{t-1}^{(2)}\right] \\
& -\left[p_{1, t-1} \mu_{t-1}^{(1)}+\left(1-p_{1, t-1} \mu_{t-1}^{(2)}\right)\right]^{2}
\end{aligned}
$$

where $j=1,2$. The measure of the conditional variance as given in Equation (5) is conditional on available information and is aggregated across regimes.

\subsection{Causality-in-Mean and Causality-in-Variance Test (Hong [1])}

Cheung and Ng's [2] test is based on equal weights being given to each lag, which does not make any distinction between recent and distant cross-correlations. This feature is not in agreement with empirical findings in the economics and finance literature that cross-correlations in financial assets decay to zero with the lag length and that the more recent information shocks should be given higher weights as they impact heavily on the current asset value. Hong [1] proposes a modified version of the Cheung and $\mathrm{Ng}$ [2] test by specifying a non-uniform kernel weighing function. We use the Bartlett kernel in this paper as a non-uniform kernel weighing function.

$$
k(j / M)= \begin{cases}1-\left|\frac{j}{(M+1)}\right|, & \text { if } \frac{j}{M+1} \leq 1 \\ 0 & \text { otherwise }\end{cases}
$$


where $M$ is the predetermined lag order. Hong [1] define a statistic $Q_{1}$ to examine the causality-in-mean and causality-in-variance and is given as:

$$
Q_{1}=\frac{\left\{T \sum_{j=1}^{T-1} k^{2}(j / M) \hat{\rho}_{u v}^{2}(j)-C_{1 T}(k)\right\}}{\left\{2 D_{1 T}(k)\right\}^{1 / 2}}
$$

where $\hat{u}_{i, t}$ and $\hat{v}_{i, t}$ are the standardized residuals obtained from the GARCH class of model, and

$$
\hat{\rho}_{u v}(j)=\left\{\hat{C}_{u u}(0) \cdot \hat{C}_{v v}(0)\right\}^{-1 / 2} \hat{C}_{u v}(j)
$$

is the sample cross-correlation between the centered standardized residuals (for testing causality-in-mean) or centered squared standardized residuals (for testing causality-in-variance) from the univariate GARCH class of models for series $\mathrm{X}$ and $\mathrm{Y}$, and

$$
\begin{gathered}
\hat{C}_{u v}(j)= \begin{cases}\frac{1}{T} \sum_{t=j+1}^{T} \hat{u}_{t} \hat{v}_{t-j}, & j \geq 0 \\
\frac{1}{T} \sum_{t=j+1}^{T} \hat{u}_{t+j} \hat{v}_{t}, & j<0\end{cases} \\
\hat{C}_{u u}(0)=\frac{1}{T} \sum_{t=j+1}^{T} \hat{u}_{t}^{2} \text { and } \hat{C}_{v v}(0)=\frac{1}{T} \sum_{t=j+1}^{T} \hat{v}_{t}^{2} \\
C_{1 T}(k)=\sum_{j=1}^{T-1}\left(1-\frac{j}{T}\right) k^{2}(j / M)
\end{gathered}
$$

and

$$
D_{1 T}(k)=\sum_{j=1}^{T-1}\left(1-\frac{j}{T}\right)\left\{1-\frac{(j+1)}{T}\right\} k^{4}(j / M)
$$

The null hypothesis for the $Q_{1}$ statistic is that there is no causality-in-mean (or causality-in-variance) at all lags from $\mathrm{X}$ to $\mathrm{Y}$.

\section{Data and Preliminary Analysis}

In order to examine the causal linkages in advanced European and Asian emerging markets as suggested by FTSE (Financial Times and the London Stock Exchange) Group, we use weekly price data of six indices associated with the respective economies: Czech Republic (PX index, an index of major stocks traded on the Prague Stock Exchange), Hungary (BUX, an index of blue-chip shares listed on the Budapest Stock Exchange Ltd.), Malaysia (FTSE Bursa Malaysia Index (FBMKLCI), a capitalization-weighted index of 30 largest firms listed on Malaysian Main Market), Poland (WIG (Warszawski Indeks Giełdowy), including all companies listed on the Warsaw Stock Exchange), Taiwan (China) (TAIEX, a capitalization-weighted index of all listed common shares traded on the Taiwan (China) Stock Exchange) and Turkey (XU100 index, a capitalization-weighted index of 100 leading stocks traded on Istanbul Stock Exchange). All the data have been obtained from the Bloomberg database. The period of 
study for all the indices is from January 1996 to April 2012 with a total of 850 observations for each index. The weekly data are associated with Wednesday. If Wednesday is a holiday, Tuesday data points are used. We have used the country name to represent the index, i.e., Czech Republic for the PX index, Hungary for the BUX index, Poland for the WIG index, Turkey for the XU100 index, Malaysia for the FBMKLCI index and Taiwan (China) for the TAIEX index.

The trading hours of the given stock exchanges are given in Table 2 in local time and in Greenwich Mean Time (GMT). The European markets operate synchronically for most of the trading period, with the Czech Republic market opening one hour and the Turkish market opening half an hour before the opening of the Hungarian and Polish markets. The Turkish and the Malaysian stock markets have a lunch break of about one and a half hours from 12:30 PM to 2:00 PM in their local timings. The Malaysian market has an overlapping trading period of two to three hours with the different European markets. On the other hand, the Taiwanese market closes before the opening of the European markets. This indicates that closing price of Taiwanese market may have a spillover effect on the opening prices of the European markets and the closing prices of the European markets may impact the next day's opening price in the Taiwanese market. The opening of the Malaysian market may be influenced by information present in the last day's European markets closing prices. Similarly, the opening prices in the European markets may be influenced by information contained in the same day's prices in the Malaysian market.

Table 3 provides the descriptive statistics of the weekly returns of advanced European and Asian markets indices. The Turkish stock market exhibits the highest mean and median returns. In other words, the European markets show the higher mean and median weekly returns than the Asian markets over the study period. The Turkish market also appears to be highly volatile in comparison to the other indices. The results based on the Jarque-Bera statistic indicate the non-normality in the weekly returns of all the indices. The significant values of the Ljung Box test up to 20 lags rejects the null of no joint autocorrelation up to 20 lags of the returns series. The significant values of the ARCH-LM test highlight the presence of heteroscedasticity in the return series and should be captured using appropriate model. The results also highlight the presence of significant negative skewness and excess kurtosis in the given return series. The results based on the ADF and KPSS tests confirm the stationarity of the given return series at $5 \%$ level of significance.

\section{Empirical Results}

\subsection{Univariate Model Specifications}

The first step in analyzing the causal inter-relationship in mean and variance is to obtain the standardized residuals. Using appropriate univariate GARCH class of models for each data series, we obtain the standardized residuals for the given series. For accounting the regime changes, we also estimate the Markov Regime 
Switching GARCH (MRS-GARCH) model. Table 4 and Table 5 present the maximum likelihood estimates of the standard GARCH model and the MRS-GARCH model.

Table 2. Stock market timings.

\begin{tabular}{ccc}
\hline Stock exchange & Local time & Greenwich mean time \\
\hline Czech & 08:00 AM to 04:20 PM & 06:00 AM to 02:20 PM \\
Hungary & 09:00 AM to 05:00 PM & 07:00 AM to 03:00 PM \\
Poland & 09:00 AM to 05:20 PM & 07:00 AM to 03:20 PM \\
Turkey & 09:30 AM to 12:30 PM, & 06:30 AM to 09:30 AM, \\
& $02: 00 \mathrm{PM}$ to 05:30 PM & 11:00 AM to 02:30 PM \\
Malaysia & $08: 30 \mathrm{AM}$ to 12:30 PM, & 00:30 AM to 04:30 AM, \\
& $02: 00 \mathrm{PM}$ to 05:00 PM & $06: 00 \mathrm{AM}$ to 09:00 AM \\
Taiwan (China) & $09: 00 \mathrm{AM}$ to 01:30 PM & $01: 00 \mathrm{AM}$ to 05:30 AM \\
\hline
\end{tabular}

Table 3. Descriptive statistics of weekly returns (\%).

\begin{tabular}{ccccccc}
\hline & Czech & Hungary & Poland & Turkey & Malaysia & Taiwan (China) \\
\hline Mean & 0.086 & 0.276 & 0.176 & 0.582 & 0.048 & 0.052 \\
Median & 0.366 & 0.504 & 0.316 & 0.773 & 0.143 & 0.203 \\
Stdev & 3.339 & 4.071 & 3.628 & 6.071 & 3.230 & 3.524 \\
Min & -16.960 & -20.054 & -17.547 & -32.837 & -13.720 & -11.607 \\
Max & 13.328 & 17.829 & 22.226 & 24.305 & 27.966 & 15.674 \\
Quartile 1 & -1.488 & -1.653 & -1.766 & -2.584 & -1.227 & -1.902 \\
Quartile 3 & 2.032 & 2.490 & 2.186 & 3.658 & 1.384 & 2.026 \\
Skewness & $-0.660^{\#}$ & $-0.623^{\#}$ & $-0.133^{\#}$ & $-0.298^{\#}$ & $0.711^{\#}$ & $-0.150^{\#}$ \\
Kurtosis & $3.482^{\#}$ & $3.381^{\#}$ & $3.445^{\#}$ & $2.892^{\#}$ & $10.483^{\#}$ & $1.326^{\#}$ \\
JB Stat & $495.022^{\#}$ & $463.569^{\#}$ & $426.447^{\#}$ & $311.732^{\#}$ & $3987.205^{\#}$ & $66.436^{\#}$ \\
ARCH-LM & $86.558^{\#}$ & $142.108^{\#}$ & $58.760^{\#}$ & $72.608^{\#}$ & $75.617^{\#}$ & $113.948^{\#}$ \\
Q(20) & $63.563^{\#}$ & $48.164^{\#}$ & $40.376^{\#}$ & $34.143^{*}$ & $58.500^{\#}$ & 20.497 \\
ADF & $-9.099^{\#}$ & $-9.421^{\#}$ & $-8.896^{\#}$ & $-9.201^{\#}$ & $-8.263^{\#}$ & $-8.261^{\#}$ \\
KPSS & 0.136 & 0.336 & 0.118 & $0.398^{\dagger}$ & 0.166 & 0.054 \\
N & 850 & 850 & 850 & 850 & 850 & 850 \\
\hline
\end{tabular}

$\#,{ }^{*}$ and $\dagger$ mean significant at $1 \%, 5 \%$ and $10 \%$ level of significance respectively. Where Stdev represents the standard deviation of returns and ARCH-LM indicates the Lagrange multiplier test for conditional heteroskedasticity with 10 lags, JB Stat indicates the Jarque Bera statistics, Q(20) statistic is the Ljung-Box test up to 20 lags.

Table 4. Maximum likelihood estimates of the standard GARCH model.

\begin{tabular}{ccccccc}
\hline & Czech & Hungary & Poland & Turkey & Malaysia & Taiwan (China) \\
\hline$\delta$ & $0.298^{\#}$ & $0.356^{\#}$ & $0.343^{\#}$ & $0.506^{\#}$ & $0.215^{\#}$ & $0.173^{\dagger}$ \\
& $(0.093)$ & $(0.122)$ & $(0.107)$ & $(0.188)$ & $(0.075)$ & $(0.103)$ \\
$\alpha_{0}$ & $1.329^{\#}$ & $1.066^{\#}$ & $0.609^{\#}$ & $0.759^{\#}$ & 0.092 & $0.451^{*}$ \\
& $(0.202)$ & $(0.152)$ & $(0.112)$ & $(0.175)$ & $(0.069)$ & $(0.207)$ \\
\hline
\end{tabular}




\section{Continued}

\begin{tabular}{ccccccc}
\hline$\alpha_{1}$ & $0.229^{\#}$ & $0.149^{\#}$ & $0.170^{\#}$ & $0.071^{\#}$ & $0.139^{*}$ & $0.126^{\#}$ \\
& $(0.031)$ & $(0.020)$ & $(0.020)$ & $(0.012)$ & $(0.060)$ & $(0.030)$ \\
$\beta_{1}$ & $0.662^{\#}$ & $0.793^{\#}$ & $0.799^{\#}$ & $0.906^{\#}$ & $0.857^{\#}$ & $0.840^{\#}$ \\
& $(0.034)$ & $(0.022)$ & $(0.018)$ & $(0.015)$ & $(0.057)$ & $(0.038)$ \\
LL & -2154.805 & -2321.329 & -2238.407 & -2656.915 & -1954.319 & -2210.929 \\
SIC & 5.108 & 5.500 & 5.305 & 6.291 & 4.636 & 5.240 \\
Q(20) & $39.945^{\#}$ & 27.280 & 26.354 & $39.775^{\#}$ & $29.745^{\dagger}$ & 18.550 \\
Qs(20) & 13.500 & 16.550 & 11.537 & 12.339 & 10.114 & 12.557 \\
ARCH-LM & 0.446 & 1.137 & 0.531 & 0.858 & 0.450 & 0.822 \\
\hline
\end{tabular}

\#, ${ }^{*}$ and $\dagger$ mean significant at $1 \%, 5 \%$ and $10 \%$ level of significance respectively.

Table 5. Maximum likelihood estimates of MRS-GARCH model.

\begin{tabular}{|c|c|c|c|c|c|c|}
\hline & Czech & Hungary & Poland & Turkey & Malaysia & Taiwan (China) \\
\hline \multirow[t]{2}{*}{$\delta^{(1)}$} & $-1.355^{\#}$ & $-1.480^{*}$ & $-0.534^{*}$ & $1.096^{\#}$ & $-3.466^{\#}$ & $0.443^{\#}$ \\
\hline & $(0.411)$ & $(0.614)$ & $(0.265)$ & $(0.265)$ & $(0.452)$ & $(0.098)$ \\
\hline \multirow[t]{2}{*}{$\delta^{(2)}$} & $0.603^{\#}$ & $0.590^{\#}$ & $0.526^{\#}$ & $0.474^{\#}$ & $0.304^{\#}$ & $-5.712^{\#}$ \\
\hline & $(0.097)$ & $(0.124)$ & $(0.124)$ & $(0.147)$ & $(0.060)$ & $(0.426)$ \\
\hline \multirow[t]{2}{*}{$\alpha_{0}^{(1)}$} & $4.856^{\#}$ & $9.334^{*}$ & $2.805^{\#}$ & $5.436^{\#}$ & 0.000 & $0.378^{*}$ \\
\hline & $(1.828)$ & $(3.893)$ & $(0.694)$ & $(2.064)$ & $(0.671)$ & $(0.148)$ \\
\hline \multirow[t]{2}{*}{$\alpha_{0}^{(2)}$} & $0.756^{*}$ & $1.400^{\#}$ & $1.223^{*}$ & 0.119 & 0.053 & 0.000 \\
\hline & $(0.367)$ & $(0.536)$ & $(0.494)$ & $(0.133)$ & $(0.034)$ & $(0.814)$ \\
\hline \multirow[t]{2}{*}{$\alpha_{1}^{(1)}$} & 0.103 & 0.078 & 0.020 & $0.187^{*}$ & 0.000 & $0.038^{*}$ \\
\hline & $(0.088)$ & $(0.097)$ & $(0.040)$ & $(0.075)$ & $(0.142)$ & $(0.021)$ \\
\hline \multirow[t]{2}{*}{$\alpha_{1}^{(2)}$} & 0.007 & 0.000 & 0.000 & 0.002 & $0.115^{\#}$ & $0.608^{\#}$ \\
\hline & $(0.052)$ & $(0.047)$ & $(0.062)$ & $(0.013)$ & $(0.020)$ & $(0.019)$ \\
\hline \multirow[t]{2}{*}{$\beta_{1}^{(1)}$} & $0.866^{\#}$ & $0.922^{\#}$ & $0.966^{\#}$ & $0.776^{\#}$ & $0.976^{\#}$ & $0.817^{\#}$ \\
\hline & $(0.148)$ & $(0.097)$ & $(0.043)$ & $(0.068)$ & $(0.260)$ & $(0.032)$ \\
\hline \multirow[t]{2}{*}{$\beta_{1}^{(2)}$} & $0.633^{\#}$ & $0.678^{\#}$ & $0.641^{\#}$ & $0.943^{\#}$ & $0.804^{\#}$ & $0.392^{\#}$ \\
\hline & $(0.071)$ & $(0.066)$ & $(0.089)$ & $(0.020)$ & $(0.023)$ & $(0.019)$ \\
\hline \multirow[t]{2}{*}{$p$} & $0.700^{\#}$ & $0.651^{\#}$ & $0.836^{\#}$ & 0.000 & $0.320^{*}$ & $0.941^{\#}$ \\
\hline & $(0.099)$ & $(0.103)$ & $(0.047)$ & $(0.383)$ & $(0.148)$ & $(0.013)$ \\
\hline \multirow[t]{2}{*}{$q$} & $0.892^{\#}$ & $0.924^{\#}$ & $0.901^{\#}$ & $0.997^{\#}$ & $0.957^{\#}$ & 0.000 \\
\hline & $(0.029)$ & $(0.025)$ & $(0.031)$ & $(0.002)$ & $(0.011)$ & $(0.058)$ \\
\hline LL & -2114.186 & -2284.355 & -2215.347 & -2627.958 & -1937.305 & -2188.143 \\
\hline$\pi_{1}$ & 0.736 & 0.822 & 0.625 & 0.997 & 0.941 & 0.056 \\
\hline$\pi_{2}$ & 0.264 & 0.178 & 0.375 & 0.003 & 0.059 & 0.944 \\
\hline SIC & 5.060 & 5.461 & 5.298 & 6.270 & 4.613 & 5.234 \\
\hline $\mathrm{Q}(20)$ & $32.184^{*}$ & 20.532 & 26.444 & $37.321^{*}$ & $29.551^{\dagger}$ & 19.647 \\
\hline Qs(20) & 11.804 & 17.393 & 12.485 & 11.976 & 9.735 & 14.493 \\
\hline ARCH-LM & 0.496 & 1.105 & 0.508 & 0.626 & 0.452 & 0.719 \\
\hline
\end{tabular}

$\#,{ }^{*}$ and $\dagger$ mean significant at $1 \%, 5 \%$ and $10 \%$ level of significance respectively. 
Insignificant values of ARCH-LM, Q(20) and Qs(20) at 5\% level of significance and higher values of LL (log-likelihood function) and lower values of SIC (Schwarz information criterion) for the maximum likelihood estimates of the MRS-GARCH model indicate that the MRS-GARCH model explains the dynamics in conditional volatility in a better way than the GARCH model.

In addition, we apply Garcia and Perron's [22] likelihood-ratio test to see if the MRS-GARCH model provides a superior characterization of the data in comparison to the standard GARCH model. Suppose $L_{1}$ and $L_{2}$ are the log-likelihood values under the null and the alternative hypotheses. The likelihood ratio test is computed as:

$$
L R=2\left(L_{2}-L_{1}\right)
$$

Table 6(a) reports the results of the likelihood ratio test for the null hypothesis that the standard GARCH model better captures the dynamics in the data. The computed LR statistic is far greater than the percentiles of the $\chi^{2}(2)$ distribution for all the indices under study.

\section{Test of Nonlinearity of Standardized Residuals}

The appropriate MRS-GARCH model captures the dynamics of the series and produces the standardized residual which we will use to analyze the causality-in-mean and causality-in-variance. Before analyzing the causality-in-mean and causality-in-variance between different markets, it is important to test the dynamics of the standardized residuals related to the given series. We make use of the McLeod-Li test and Tsay's Test for nonlinearity to understand the dynamics of the series (standardized residuals) which we will use for analyzing the causality-in-mean and causality-in-variance between different markets. The Null hypothesis of the McLeod-Li test is that the given time series follows an ARIMA process and the null hypothesis of the Tsay's Test for nonlinearity is that the given time series follows an AR process. Table 6(b) reports the p-values of both the tests. Results indicate that the null hypothesis for both the tests are not rejected indicating that the given standardized residuals series follow linear dynamics.

Table 6. (a) Likelihood ratio test; (b) Test of non-linearity of the standardized residuals.

(a)

\begin{tabular}{ccccc}
\hline & $L_{1}$ & $L_{2}$ & LR & p-value \\
\hline Czech & -2154.805 & -2114.186 & $81.237^{\#}$ & 0.000 \\
Hungary & -2321.329 & -2284.355 & $73.949^{\#}$ & 0.000 \\
Poland & -2238.407 & -2215.347 & $46.120^{\#}$ & 0.000 \\
Turkey & -2656.915 & -2627.958 & $57.915^{\#}$ & 0.000 \\
Malaysia & -1954.319 & -1937.305 & $34.027^{\#}$ & 0.000 \\
Taiwan (China) & -2210.929 & -2188.143 & $45.571^{\#}$ & 0.000 \\
\hline
\end{tabular}

\# means significant at $1 \%$ level of significance. 
(b)

\begin{tabular}{ccc}
\hline & McLeod-Li test & Tsay's Test \\
\hline Czech & 0.901 & 0.123 \\
Hungary & 0.164 & 0.692 \\
Poland & 0.836 & 0.735 \\
Turkey & 0.985 & 0.914 \\
Malaysia & 1.000 & 0.267 \\
Taiwan (China) & 0.997 & 0.365 \\
\hline
\end{tabular}

\subsection{Hong [1] Causality Tests for Advanced European and Asian Economies}

Causality-in-Mean and Causality-in-Variance Tests

Next, we apply Hong's causality tests on the standardized residuals obtained from the respective MRS-GARCH models to test the causality-in-mean relationship in advanced emerging European and Asian economies. Table 7 reports the results of the causality-in-mean test for the stock markets under study. The results indicate that the Czech Republic exhibits causality-in-mean relationship for Hungary and Poland. On the flip side, Hungary exhibits moderate evidence of a causality-in-mean relationship with the Czech Republic. In addition, Hungary and Poland exhibit a bidirectional causality-in-mean relationship with Taiwan (China). The stock returns in the Turkish market unidirectionally cause the stock returns of Hungarian and Polish stock markets. Turkey also shows weak evidence of a return spillover effect to Taiwan (China). The Asian markets (Malaysia and Taiwan (China)) exhibit strong evidence of a return spillover effect to two major European markets, i.e., Hungary and Poland. The results also suggest causality-in-mean from Malaysia to Taiwan (China). However, the reverse relationship is insignificant indicating no return spillover from Taiwan (China) to Malaysia.

We also examine the indirect causal relationship among advanced emerging European and Asian countries as suggested by Hsiao [23]. Although we do not find a direct causality-in-mean effect from Hungary to Poland, Hungary indirectly causes Poland in a way that Hungary causes the Czech Republic and the Czech Republic causes Poland. Such indirect causality-in-mean effect can also be seen between Hungary and Poland (Hungary $\rightarrow$ Taiwan (China), Taiwan (China) $\rightarrow$ Poland, Hungary $\rightarrow$ Poland), Poland and Hungary (Poland $\rightarrow$ Taiwan (China), Taiwan (China) $\rightarrow$ Hungary, hence, Poland $\rightarrow$ Hungary), Poland and Czech Republic (Poland $\rightarrow$ Taiwan (China), Taiwan (China) $\rightarrow$ Czech Republic, hence, Poland $\rightarrow$ Czech Republic), Turkey and Czech Republic (Turkey $\rightarrow$ Hungary, Hungary $\rightarrow$ Czech Republic, hence, Turkey $\rightarrow$ Czech Republic) and Malaysia and Czech Republic (Malaysia $\rightarrow$ Hungary, Hungary $\rightarrow$ Czech Republic, hence, Malaysia $\rightarrow$ Czech Republic). Overall, the results of Hong's [1] causality-in-mean indicate the presence of bivariate, intra-regional, inter-regional and indirect causality-in-mean relationships among advanced emerging European and Asian economies. In order to investigate the causal linkages in the second moment of market returns, we apply Hong's causality-in-variance test based on squared 
standardized residuals obtained from the respective MRS-GARCH models.

Table 8 presents the results of Hong's [1] causality-in-variance for all the indices under study. We observe evidence of volatility spillover from the Malaysian market to the Hungarian and Polish markets for the whole sample. The results indicate no causal relationships among the other markets under study. We do not find any evidence of intra-regional volatility spillover effect in advanced emerging European and Asian markets.

The literature also provides evidence in support of the notion that the first order and second order causal relationships among markets may vary dynamically over time and provide different inferences in stable and volatile environments (Fujii [24]).

Table 7. Causality-in-mean test results.

\begin{tabular}{|c|c|c|c|c|}
\hline & $M=1$ & $M=2$ & $M=3$ & $M=4$ \\
\hline Czech Republic $\rightarrow$ Hungary & $2.698^{\#}$ & $2.988^{\#}$ & $3.561^{\#}$ & $4.023^{\#}$ \\
\hline Czech Republic $\rightarrow$ Poland & 1.104 & 1.358 & $1.906^{\dagger}$ & $2.372^{*}$ \\
\hline Czech Republic $\rightarrow$ Turkey & -0.587 & -0.380 & 0.154 & 0.645 \\
\hline Czech Republic $\rightarrow$ Malaysia & -0.689 & -0.783 & -0.680 & -0.476 \\
\hline Czech Republic $\rightarrow$ Taiwan (China) & -0.024 & 0.290 & 0.697 & 1.262 \\
\hline Hungary $\rightarrow$ Czech Republic & 1.171 & 0.965 & 1.345 & $1.835^{\dagger}$ \\
\hline Hungary $\rightarrow$ Poland & 0.668 & 1.002 & 1.363 & 1.593 \\
\hline Hungary $\rightarrow$ Turkey & 0.200 & 0.205 & 0.341 & 0.537 \\
\hline Hungary $\rightarrow$ Malaysia & -0.584 & -0.507 & -0.294 & -0.066 \\
\hline Hungary $\rightarrow$ Taiwan (China) & 1.604 & $2.397^{*}$ & $3.156^{\#}$ & $3.711^{\#}$ \\
\hline Poland $\rightarrow$ Czech Republic & -0.031 & 0.069 & 0.103 & 0.091 \\
\hline Poland $\rightarrow$ Hungary & -0.057 & 0.685 & 1.195 & 1.474 \\
\hline Poland $\rightarrow$ Turkey & -0.704 & -0.443 & -0.170 & 0.004 \\
\hline Poland $\rightarrow$ Malaysia & -0.449 & -0.039 & 0.182 & 0.259 \\
\hline Poland $\rightarrow$ Taiwan (China) & 1.289 & $1.657^{\dagger}$ & $1.846^{\dagger}$ & $1.892^{\dagger}$ \\
\hline Turkey $\rightarrow$ Czech Republic & -0.355 & -0.353 & -0.029 & 0.365 \\
\hline Turkey $\rightarrow$ Hungary & $3.200^{\#}$ & $3.748^{\#}$ & $4.429^{\#}$ & $4.964^{\#}$ \\
\hline Turkey $\rightarrow$ Poland & $2.786^{\#}$ & $2.618^{\#}$ & $3.101^{\#}$ & $3.776^{\#}$ \\
\hline Turkey $\rightarrow$ Malaysia & -0.431 & -0.456 & -0.450 & -0.466 \\
\hline Turkey $\rightarrow$ Taiwan (China) & -0.350 & 0.591 & 1.450 & $1.975^{*}$ \\
\hline Malaysia $\rightarrow$ Czech Republic & 0.693 & 0.760 & 1.190 & 1.609 \\
\hline Malaysia $\rightarrow$ Hungary & $2.627^{\#}$ & $2.408^{*}$ & $2.547^{*}$ & $2.748^{\#}$ \\
\hline Malaysia $\rightarrow$ Poland & $2.306^{*}$ & $2.196^{*}$ & $2.577^{\star}$ & $3.035^{\#}$ \\
\hline Malaysia $\rightarrow$ Turkey & -0.465 & -0.419 & -0.292 & -0.094 \\
\hline Malaysia $\rightarrow$ Taiwan (China) & $4.138^{\#}$ & $4.070^{\#}$ & $3.942^{\#}$ & $3.796^{\#}$ \\
\hline Taiwan (China) $\rightarrow$ Czech Republic & 1.301 & 1.357 & $1.700^{\dagger}$ & $2.025^{*}$ \\
\hline Taiwan (China) $\rightarrow$ Hungary & $3.954^{\#}$ & $4.257^{\#}$ & $4.465^{\#}$ & $4.598^{\#}$ \\
\hline Taiwan (China) $\rightarrow$ Poland & $6.024^{\#}$ & $6.135^{\#}$ & $6.209^{\#}$ & $6.186^{\#}$ \\
\hline Taiwan (China) $\rightarrow$ Turkey & 0.215 & 0.734 & 1.118 & 1.293 \\
\hline Taiwan (China) $\rightarrow$ Malaysia & 0.692 & 0.708 & 0.628 & 0.492 \\
\hline
\end{tabular}

$\#,{ }^{*}$ and $\dagger$ mean significant at $1 \%, 5 \%$ and $10 \%$ level of significance, respectively. 
Table 8. Causality-in-variance test results.

\begin{tabular}{|c|c|c|c|c|}
\hline & $M=1$ & $M=2$ & $M=3$ & $M=4$ \\
\hline Czech Republic $\rightarrow$ Hungary & -0.610 & -0.587 & -0.611 & -0.546 \\
\hline Czech Republic $\rightarrow$ Poland & -0.701 & -0.686 & -0.718 & -0.789 \\
\hline Czech Republic $\rightarrow$ Turkey & -0.047 & -0.208 & -0.357 & -0.487 \\
\hline Czech Republic $\rightarrow$ Malaysia & -0.706 & -0.824 & -0.700 & -0.493 \\
\hline Czech Republic $\rightarrow$ Taiwan (China) & 0.023 & -0.149 & -0.325 & -0.459 \\
\hline Hungary $\rightarrow$ Czech Republic & -0.685 & -0.710 & -0.754 & -0.793 \\
\hline Hungary $\rightarrow$ Poland & -0.704 & -0.846 & -0.972 & -1.084 \\
\hline Hungary $\rightarrow$ Turkey & -0.596 & -0.699 & -0.704 & -0.663 \\
\hline Hungary $\rightarrow$ Malaysia & 0.706 & 0.513 & 0.286 & 0.124 \\
\hline Hungary $\rightarrow$ Taiwan (China) & -0.655 & -0.269 & -0.043 & 0.006 \\
\hline Poland $\rightarrow$ Czech Republic & 0.687 & 0.507 & 0.292 & 0.099 \\
\hline Poland $\rightarrow$ Hungary & -0.556 & -0.699 & -0.805 & -0.883 \\
\hline Poland $\rightarrow$ Turkey & -0.486 & -0.636 & -0.530 & -0.384 \\
\hline Poland $\rightarrow$ Malaysia & 0.352 & 0.356 & 0.427 & 0.475 \\
\hline Poland $\rightarrow$ Taiwan (China) & -0.654 & -0.568 & -0.518 & -0.533 \\
\hline Turkey $\rightarrow$ Czech Republic & 0.213 & 0.083 & -0.079 & -0.239 \\
\hline Turkey $\rightarrow$ Hungary & 0.561 & 0.387 & 0.201 & 0.058 \\
\hline Turkey $\rightarrow$ Poland & -0.633 & -0.781 & -0.863 & -0.922 \\
\hline Turkey $\rightarrow$ Malaysia & -0.708 & -0.830 & -0.936 & -1.008 \\
\hline Turkey $\rightarrow$ Taiwan (China) & -0.253 & 0.491 & 0.926 & 1.052 \\
\hline Malaysia $\rightarrow$ Czech Republic & 1.377 & 1.277 & 1.094 & 0.933 \\
\hline Malaysia $\rightarrow$ Hungary & $7.660^{\#}$ & $7.298^{\#}$ & $6.674^{\#}$ & $6.073^{\#}$ \\
\hline Malaysia $\rightarrow$ Poland & $8.254^{\#}$ & $7.870^{\#}$ & $7.235^{\#}$ & $6.628^{\#}$ \\
\hline Malaysia $\rightarrow$ Turkey & -0.503 & -0.658 & -0.808 & -0.934 \\
\hline Malaysia $\rightarrow$ Taiwan (China) & -0.543 & -0.670 & -0.728 & -0.772 \\
\hline Taiwan (China) $\rightarrow$ Czech Republic & -0.705 & -0.832 & -0.852 & -0.823 \\
\hline Taiwan (China) $\rightarrow$ Hungary & -0.426 & -0.561 & -0.678 & -0.773 \\
\hline Taiwan (China) $\rightarrow$ Poland & -0.677 & -0.464 & -0.352 & -0.352 \\
\hline Taiwan (China) $\rightarrow$ Turkey & -0.312 & -0.346 & -0.389 & -0.441 \\
\hline Taiwan (China) $\rightarrow$ Malaysia & 0.027 & -0.064 & -0.163 & -0.267 \\
\hline
\end{tabular}

$\#,{ }^{*}$ and $\dagger$ mean significant at $1 \%, 5 \%$ and $10 \%$ level of significance, respectively.

\section{Conclusions}

This paper examines the causal linkages among advanced emerging European and Asian economies using weekly data of their stock indices over the sample period January 1996 to April 2012. We apply Hong's [1] causality-in-mean and causality-in-variance tests to achieve our goal. First of all, we compare the max- 
imum likelihood estimates of GARCH models and MRS-GARCH model to identify the volatility model that can better explain the dynamics underlying the data. The MRS-GARCH model comes out as the winner because it takes into account regime shifts over the sample period which can be important for modeling the dynamics of volatility. The standardized residuals and the squared standardized residuals from the MRS-GARCH model (for the different indices under study) act as inputs in Hong's [1] causality tests to examine the return and volatility spillover among advanced emerging European and Asian stock markets. The results indicate that the direct and contemporaneous casual linkages among the markets are weak. Our findings indicate that out of the 30 possible causality-in-mean relationships, only 14 turn out to be statistically significant. On the other hand, out of the 30 causality-in-variance linkages, only two pairs exhibit significant causal linkages. We also find indirect causality-in-mean relationships between Poland and Hungary, Poland and the Czech Republic, Turkey and the Czech Republic and Malaysia and the Czech Republic. The analysis of the significant direct and indirect causal relationships suggests the presence of both inter-regional and intra-regional spillover effects among advanced emerging European and Asian economies.

Our findings suggest that institutional investors and portfolio managers should consider causal linkages among stock markets while investing in offshore markets for diversification benefits. In particular, our findings will be of value to investors investing in multiple markets having different economic conditions who are concerned about the return and volatility spillover among markets. In addition, our findings have important implications towards implementing trading strategies and the evaluation of investment and asset allocation decisions by portfolio managers, financial analysts and institutional investors such as pension funds.

\section{Conflicts of Interest}

The author declares no conflicts of interest regarding the publication of this paper.

\section{References}

[1] Hong, Y. (2001) A Test for Volatility Spillover with Application to Exchange Rates. Journal of Econometrics, 103, 183-224. https://doi.org/10.1016/S0304-4076(01)00043-4

[2] Cheung, Y.W. and Ng, L.K. (1996) A Causality-in-Variance Test and Its Application to Financial Market Prices. Journal of Econometrics, 72, 33-48. https://doi.org/10.1016/0304-4076(94)01714-X

[3] Billio, M. and Pelizzon, L. (2003) Volatility and Shocks Spillover before and after EMU in European Stock Markets. Journal of Multinational Financial Management, 13, 323-340. https://doi.org/10.1016/S1042-444X(03)00014-8

[4] Baele, L. (2005) Volatility Spillover Effects in European Equity Markets. Journal of Financial and Quantitative Analysis, 40, 373-401. https://doi.org/10.1017/S0022109000002350 
[5] Kim, J.S., Moshirian, F. and Wu, E. (2005) Dynamic Stock Market Integration Driven by the European Monetary Union: An Empirical Analysis. Journal of Banking and Finance, 29, 2475-502. https://doi.org/10.1016/j.jbankfin.2004.09.002

[6] Bartram, S., Taylor, S. and Wang, Y. (2007) The Euro and European Financial Market Integration. Journal of Banking and Finance, 31, 1461-1481. https://doi.org/10.1016/j.jbankfin.2006.07.014

[7] Savva, C., Osborn, D. and Gill, L. (2009) Spillovers and Correlations between US and Major European Stock Markets: The Role of the Euro. Applied Financial Economics, 19, 1595-1604. https://doi.org/10.1080/09603100802599563

[8] Koutmos, G. (1996) Modeling the Dynamic Interdependence of Major European Stock Markets. Journal of Business, Finance, and Accounting, 23, 975-988. https://doi.org/10.1111/j.1468-5957.1996.tb01035.x

[9] Baig, T. and Goldfajn, I. (1999) Financial Market Contagion in the Asian Crises. Staff Papers 46. International Monetary Fund, Washington DC, 167-195.

[10] Forbes, K. and Rigobon, R. (2002) No Contagion, Only Interdependence: Measuring Stock Market Comovement. Journal of Finance, 57, 2223-2261. https://doi.org/10.1111/0022-1082.00494

[11] Fratzscher, M. (2002) Financial Market Integration in Europe: On the Effects of EMU on Stock Markets. International Journal of Finance and Economics, 7, 165-193. https://doi.org/10.1002/ijfe.187

[12] Maneschiold, P.O. (2005) International Diversification Benefits between US, Turkish and Egyptian Stock Markets. Review of Middle East Economics and Finance, 3, 115-133. https://doi.org/10.1080/14753680500166458

[13] Soofi, A.S. (2008) Global Financial Integration and the MENA Countries: Evidence from Equity and Money Markets. Review of Middle East Economics and Finance, 4, 93-116. https://doi.org/10.2202/1475-3693.1102

[14] Lee, S.J. (2009) Volatility Spillover Effects among Six Asian Countries. Applied Economics Letters, 16, 501-508. https://doi.org/10.1080/13504850601018700

[15] Henry, O.T., Olekalns, N. and Lakshman, R.W.D. (2007) Identifying Interdependencies between South-East Asian Stock Markets: A Non-Linear Approach. Australian Economic Papers, 46, 122-135. https://doi.org/10.1111/j.1467-8454.2007.00309.x

[16] Singh, P., Kumar, B. and Pandey, A. (2010) Price and Volatility Spillovers across North American, European and Asian Stock Markets. International Review of Financial Analysis, 19, 55-64. https://doi.org/10.1016/j.irfa.2009.11.001

[17] Beirne, J., Caporale, G.M., Ghattas, M.S. and Spagnolo, N. (2010) Global and Regional Spillovers in Emerging Stock Markets: A Multivariate GARCH-in-Mean Analysis. Emerging Markets Review, 11, 250-260. https://doi.org/10.1016/j.ememar.2010.05.002

[18] Granger, C.W.J. (1969) Investigating Causal Relations by Econometric Models and Cross-Spectral Methods. Econometrica, 37, 424-438. https://doi.org/10.2307/1912791

[19] Cai, J. (1994) A Markov Model of Unconditional Variance in ARCH. Journal of Business and Economic Statistics, 12, 309-316.

[20] Hamilton, J.D. and Susmel, R. (1994) Autoregressive Conditional Heteroscedasticity and Changes in Regime. Journal of Econometrics, 64, 307-333. https://doi.org/10.1016/0304-4076(94)90067-1

[21] Gray, S.F. (1996) Modeling the Conditional Distribution of Interest Rates as a Re- 
gime-Switching Process. Journal of Financial Economics, 42, 27-62.

https://doi.org/10.1016/0304-405X(96)00875-6

[22] Garcia, R. and Perron, P. (1996) An Analysis of the Real Interest Rate under Regime Shifts. Review of Economics and Statistics, 78, 111-125. https://doi.org/10.2307/2109851

[23] Hsiao, C. (1982) Autoregressive Modeling and Causal Ordering of Economic Variables. Journal of Economic Dynamics and Control, 4, 243-259. https://doi.org/10.1016/0165-1889(82)90015-X

[24] Fujii, E. (2005) Intra and Inter-Regional Causal Linkages of Emerging Stock Markets: Evidence from Asia and Latin America in and out of Crises. Journal of International Financial Markets, Institutions and Money, 15, 315-342.

https://doi.org/10.1016/j.intfin.2004.07.001 